Sheridan, L. P., North, A. C., \& Scott, A. J. (2014). Experiences of stalking in same-sex and opposite-sex contexts. Violence and Victims, 29(6), 1014-1028

\begin{abstract}
The majority of the stalking literature reports on male stalkers and female victims. The current work examines stalking experiences in four sex dyads: male stalker-female victim, female stalker-male victim, female-female dyads, and male-male dyads. Respondents were 872 self defined victims of stalking from the UK and the USA who completed an anonymous survey. The study variables covered the process of stalking, impact on victims and third parties, and victim responses to stalking. Under $10 \%$ of comparisons were significant, indicating that sex of victim and stalker is not a highly discriminative factor in stalking cases. Female victims of male stalkers were most likely to suffer physical and psychological consequences. Female victims reported more fear than did males, and the majority of significant differences conformed to sex role stereotypes. Earlier work suggested stalker motivation and prior victim-stalker relationship as important variables in analyses of stalking, but these did not prove significant in the current work, perhaps because of sampling differences.
\end{abstract}

Keywords: harassment; dyads; gender; victims. 


\section{Experiences of Stalking in Same-Sex and Opposite-Sex Contexts}

It it is well known that the typical stalker is male, and his modal victim female (e.g., Bjerregaard, 2002; Meloy, 1999). This is the case when all stalker subtypes are examined, and when stalking between prior intimates is considered in isolation (see Nicastro, Cousins, \& Spitzberg, 2000). As would be expected, the majority of the literature examines stalking related issues in respect of female victims and male perpetrators. A minority of recent studies have directly examined female stalkers (Meloy \& Boyd 2003; Meloy, Mohandie \& Green, 2011; Purcell, Pathé \& Mullen, 2001), male victims (Englebrecht \& Reyns, 2011), and same sex stalking (Pathé, Mullen \& Purcell, 2000; Strand \& McEwan, 2011; Strand \& McEwan, 2012). These works have tended to focus on describing or comparing one or two subgroups or dyads, for instance, male stalkers and female stalkers. The present paper, based on a large dataset, adopts a unique approach by comparing the experiences of four subgroups of victims, categorised according to the sex of stalker and victim: male stalkers with female victims, female stalkers with male victims, female-female stalkers, and male-male stalkers. The four subgroups will be compared on variables pertaining to the stalking process, the consequences of stalking, and victim responses, in order to increase knowledge of the distance and overlap between sex dyads in stalking cases.

\section{Opposite Sex Stalking}

Following a meta-analysis of 175 studies of stalkers and their victims, Spitzberg and Cupach (2007) indicated that although women are more likely than men to experience stalking victimisation ( $28.5 \%$ lifetime risk for females, $11 \%$ lifetime risk for males), female victims may be nonetheless over represented in clinical and forensic samples. It is also often stated that men are less likely to self-identify as stalking victims. Indeed, Englebrecht and Reyns' (2011) study based on a large community survey found that men had higher thresholds for self-identifying as victims of stalking (usually requiring a physical assault) than their female counterparts. Overall, however, $40 \%$ of men and 39\% of women who met the study's criteria for stalking self-identified themselves as victims. In McNamara and Marsil's (2012) examination of the disparity between researcher- and college 
student-identified victim status, $26 \%$ of women and $22 \%$ of men self-identified as stalking victims. Whilst individual stalking behaviours and other factors are likely subject to sex differences in terms of recognition of one's own victim status, there do not seem to be massive sex differences in terms of wholesale recognition.

Another area where the research evidence defies common expectations concerns stalking and gendered violence. Works that reveal men and women to be equally violent stalkers include Harmon, Rosner and Owens (1998); Meloy and Boyd (2003); Purcell et al. (2001); Thomas, Purcell, Pathé and Mullen (2008); and Strand and McEwan (2012). Strand and McEwan compared 71 female with 479 male stalkers, finding that $31 \%$ of men were violent, as compared with $23 \%$ of women. This difference was not statistically significant. In both sexes violent behaviour was best predicted by prior stalker-victim relationship, threats, and approach behaviour. In a unique study, Reavis, Allen and Meloy (2008) found male and female stalkers to be equally psychopathic. Meloy et al. (2011) examined 143 female stalkers, comparing them with 862 male stalkers. Male stalkers were more likely than female stalkers to target the opposite sex, but less likely to be triggered by a precipitating event. Men were more likely to target ex-intimates, while women were more likely to target celebrities. Women were more likely to send letters and gifts but less likely to approach victims. Men's harassment was more proximity based and less benign, whereas women were significantly less likely to threaten and attack. However, when only ex-intimates were compared, the violence rate was the same within both sexes. It is worth noting that Meloy et al. (2011) included celebrity harassers in their sample, whose profiles tend to differ from those of other stalkers, in that celebrity harassers are more likely to be mentally ill and less likely to know their victims personally (Hoffmann \& Sheridan, 2008). In a 2002 study of US students, Sinclair and Frieze (2002) found that female stalkers committed higher levels of moderate violence, and higher rates of violence by female stalkers were also identified by Dutton and Winstead (2006).

A useful study was conducted by Thompson, Dennison, and Stewart (2012) who examined, among a sample of Australian students, whether male and female relational stalkers perpetrated 
different rates of moderate and severe stalking violence. They also investigated what socio-cultural beliefs may account for any sex differences or similarities. These authors noted that many previous studies of female versus male stalking violence may be skewed, given that men are less likely to self-identify as victims and report to the police, and report feeling fearful than women (but see above). As in the Sinclair and Frieze (2002) and the Dutton and Winstead (2006) works, Thompson et al. (2012) examined the frequency of perpetration of stalking behaviours among student samples and did not incorporate a fear requirement. Of 712 students, $41 \%$ were classed as relational stalkers. Women were more likely to engage in actual or attempted moderate violence, but men and women perpetrated (and attempted to perpetrate) severe violence at similar rates. In terms of socio-cultural beliefs, both sexes were more supportive of justifications for female-perpetrated rather than maleperpetrated relational violence. Male perpetrators of severe violence were more likely to believe their actions had frightened, intimidated or harmed than the female perpetrators of same. This evidence is a clear indication that if sample sizes allow, severe violence should be examined separately in studies that focus on sex differences in stalking. Contrary to Thompson et al.'s (2012) results, severe violence has been shown to have its own correlates in the stalker violence prediction literature and would appear to be more frequently perpetrated by males (e.g., James \& Farnham, 2003; Rosenfeld \& Lewis, 2005).

\section{Same-Sex Stalking}

When sex of both victims and perpetrators is examined, some notable differences arise. Data from several large scale representative governmental surveys from Australia, the UK, and the USA produce convergent figures on same-sex stalking. Rates of male-male stalking range from 50\% to $62 \%$ of cases where victims were male, and female-female stalking rates range from $9 \%$ to $25 \%$ of cases where victims were female (ABS, 2010; Baum, Catalano, Rand \& Rose, 2009; Budd \& Mattinson, 2000; Tjaden \& Thoennes, 1998). Almost one in four of Purcell, Pathé and Mullen’s (2002) victims identified via a large scale random community survey were stalked by a perpetrator of the same sex. The nature of the prior relationship did not significantly differ by victim sex, and 
again men were more likely to be stalked by someone of the same sex than were women. Findings from these large scale epidemiological studies have been mirrored by some smaller victim studies. In a review of the literature, Strand and McEwan (2011) concluded that at least a quarter of adult stalking cases involve same-sex stalking, and that the numbers may be higher among juvenile populations. Furthermore, the data suggest that around half of male victims will be stalked by other men, and that around one in six female victims will be stalked by other women.

Two studies have examined whether the nature of same-sex stalkers differs from that of opposite-sex stalkers in any notable ways. Pathé et al.’s (2000) Australian study examined 163 stalkers, of whom $29(18 \%)$ had targeted a victim of their own sex: $18(62 \%)$ were women and 21 (71\%) were heterosexual. Same-sex stalkers were less likely than opposite-sex stalkers to follow or approach their victims, but no significant differences were found in relation to threats or violent and destructive actions. Neither were there any significant differences between same-sex and oppositesex stalkers when it came to psychiatric diagnosis. More recently, Strand and McEwan (2011) examined 94 stalkers from Australia and Sweden. The former were referred to a forensic clinic and information on the latter was obtained from police cases. Three subgroups were identified: women who stalked only women, men who stalked only men, and those who targeted multiple victims where at least one victim was of the same sex. The first two groups were very similar in terms of demographic and offence characteristics, though women were more likely to write letters and to send e-mails. The multiple-victim group differed from the other two groups, however. They were more likely to be the ex-intimate of one of their victims, and as such were more likely to be of the 'rejected' (as compared with the 'resentful') stalker subtype (see Mullen, Pathé, \& Purcell, 2009); and were also more likely to spy and loiter.

When Strand and McEwan (2011) compared same-sex with opposite-sex stalkers, the groups did not differ significantly in terms of stalker age, duration of the stalking, mental illness frequency, ex-intimate status, or frequency of violence. However, more female stalkers were in the same-sex group and more male stalkers were in the opposite-sex group. Also, same-sex stalkers 
were more likely to be charged with threats and other offences, they existed more often among neighbours of the victim and less often among strangers, and they were more likely to enter the victim's home and damage property and threaten. Like Pathé et al. (2000), Strand and McEwan (2011) concluded that the main differences between opposite-sex and same-sex stalkers concern motives and the nature of the prior stalker-victim relationship. That is, opposite-sex stalkers are mainly motivated by a need for intimacy and sex, whilst same-sex stalkers are motivated more by grievance. As such, it is unsurprising that same-sex stalkers are more likely to threaten. It is also important to note that although ex-intimates are generally believed to be the most violent stalker subtype (e.g., Rosenfeld, 2004), one in eight of the same-sex stalkers described by Strand and McEwan committed a violent assault, and just one of these was a former intimate.

One study has directly assessed the frequency and antecedents of stalking in a population of 165 gay men, lesbians, bisexuals and transgendered individuals (Derlega et al., 2011). As seen among (presumably) largely heterosexual samples, men were more likely to engage in pursuit behaviour at the end of a relationship than were women. This work also supported the conclusions of previous research that identified a positive relationship between post-relational stalking and the extent of the stalker's investment in the relationship (e.g., Rusbult, Martz, \& Agnew, 1988). It is not known whether the frequency of stalking of former intimates is impacted by sexual orientation.

\section{The Current Study}

The research evidence indicates that female victims of stalking significantly outnumber male victims. Given high base rates of stalking, however, male victims are not scarce. The research evidence suggests that female and male stalkers can be equally violent, with the possible exception of severe violence which may be more commonly perpetrated by males. It also appears that most same-sex stalkers are heterosexual. Some of the prior works have compared male stalkers with female stalkers, and others have compared same-sex with opposite-sex stalkers. The current work is unique in that it covers both of these factors by comparing four distinct dyads of stalking victims: male-male cases, male-female cases, female-male cases, and female-female cases. Comparisons are 
made across a wide range of variables covering the stalking process, impact on victims and third parties, and victim responses to being stalked.

\section{Method}

\section{Participants}

An anonymous questionnaire relating to respondents' stalking victimisation was completed by 1,036 self-defined stalking victims from the UK and the USA. One hundred and sixty four respondents were excluded from the dataset because the stalking period was less than four weeks and/or constituted fewer than 10 occasions [following Pathé et al (2000) criteria for persistence and repetition], because the stalker's identity and therefore sex was unknown, due to suspicion that the respondent was delusional, was a stalker, was aged under 18 years when the stalking began, or was not describing an episode of stalking as described by the prior literature. This resulted in a final sample of 872 respondents: $502(60 \%)$ from the UK and $370(40 \%)$ from the US. The mean age of respondents when the stalking began was 33.68 years $(S D=10.54$, range 18 to 79$)$. A large majority $(87 \%)$ of victims were female. With regard to the sex of victims and their stalkers, 662 (75.9\%) respondents were women stalked by men, 96 respondents $(11 \%)$ were women stalked by women, 72 respondents $(8.3 \%)$ were men stalked by women, and 42 respondents $(4.8 \%)$ were men stalked by men. A total of $15.8 \%$ were stalked by a person of the same sex.

\section{Materials}

An eight-section questionnaire was utilised, covering 29 pages and comprising 349 closed and 59 open questions. The questionnaire was created by the first author and was previously employed in studies by Sheridan and Grant (2007) and Sheridan and Lyndon (2012), although the data reported here are unique. Sections one and two obtained comparable demographic information about the victim and the stalker, and responses were a mix of open (e.g. country of origin; country of residence, occupation) and closed (e.g. pertaining to ethnicity and marital status) questions. 
Section three asked about stalking behaviour, and open questions here included when the stalking started, how it ended (if applicable), the perceived trigger for the stalking, how the respondent first realised they were being stalked, and who (if anyone) aided the stalker. Closed questions requiring a simple 'yes/no' response included a list of 30 stalking behaviours (where respondents were asked to indicate any they had experienced), and closed questions with several options included those pertaining to sources used by the stalker to gather victim-related information, and whether the stalker harassed third parties (with respondents indicating all that were applicable).

Section four asked about official and non-official responses of others to the stalking. Examples of open questions here concerned how many harassing incidents respondents experienced before reporting to the police and why cases that were reported to the police did not reach the courts. Closed questions in section four included ratings along Likert scales concerning how helpful various agencies and individuals had proven to be. Section five considered victims' recommendations for best practice, and were open, asking victims their opinions on police training, how stalkers may best be stopped, and when stalking truly ends for victims. Section six focussed on the support available for victims of stalking, asking what type of interventions were or would likely be most useful (e.g. helplines, information packs). The majority of questions here were open. Section seven asked about the victim's direct and non-direct responses to the stalking, being comprised mainly of closed questions that concerned whether victims used coping strategies (e.g. staying indoors, substance use), responded to the stalker, and whether these reactions were beneficial. Section eight focused on the effects of stalking, specifically the physical, psychological, social and economic consequences. Again, questions were principally of a closed nature requiring ‘yes/no' responses.

The dependent variables were 'yes/no' responses to questions concerning (i) 45 variables relating the stalking process; (ii) 19 social/financial consequences of being stalked, 12 psychological consequences, and 11 physical consequences; (iii) 11 variables concerned with the 
effects on third parties, and; (iv) 18 variables covering victim responses. Individual variables are summarised below.

(i) Stalking process (section three of the questionnaire): prior stalker-victim relationship, perceived motivations and triggers, whether the victim was taken seriously (by friends, family and official bodies), how frightened the victim was, whether the stalker was aided (wittingly or unwittingly), whether the stalker obtained victim-related information from third parties, whether or not the victim was stalked by the internet, from overseas, was followed, received unsolicited telephone calls, emails, text messages, received paper communications, other communications, was photographed, had pets abused, pets threatened, had home/car/other property vandalised, was physically assaulted, sexually assaulted, received personal threats, threats to harm others, was burgled, whether the stalker visited the victim's home and other relevant locations, was spied upon, received unwanted items and gifts, was subject to malicious gossip, whether third parties were harassed or manipulated.

(ii) Questions concerning the effects on victims were broken down into two sets, as follows.

Social/financial consequences (section eight of the questionnaire): whether or not the victim, as a result of being stalked, changed job or course, moved house, gave up social activities, changed phone number, changed e-mail address, had work performance adversely affected, reduced contact with family and friends, lost contact with family and friends, changed or sold their car, repaired damaged property, changed identity, suffered the expense of counselling, expense of therapies, expense of legal advice, expense of security systems, reduced their working hours, or used annual leave to deal with stalking-related problems.

Psychological and physical consequence (section eight of the questionnaire) s: suicidal thoughts, suicide attempts, depression, anxiety, anger, confusion, fear, increased distrust, aggression, paranoia, irritation, agoraphobia, weight changes, change in appetite, sleep disturbances, headaches, 
tiredness, nausea, weakness, self-harm, purging (the use of laxatives, forced vomiting), physical injuries (inflicted by the stalker) and panic attacks.

(iii) Effects on third parties (section three of the questionnaire). Whether a range of other persons were adversely affected, i.e. partner, parents, children, other family members, friends, work colleagues, clients, neighbours, acquaintances, strangers, and others.

(iv) Victim responses (section seven of the questionnaire). Whether the victim kept a log, reported to the police and other agencies, collected evidence, had a safety plan, changed routine, stayed indoors more, carried a weapon, confronted, threatened or attacked the stalker, attacked the stalker, asked the stalker to leave them alone, answered the phone, replied to e-mails, replied to text messages, asked the stalker why.

\section{Procedure}

Following an international press release, and a series of television, radio and newspaper interviews (e.g. BBC on-line news, BBC World Service), self identifying victims of stalking were directed to a website where they could complete an online questionnaire or request a paper copy Potential respondents were informed that the study aimed to build a better understanding of stalking victimisation. Links to this website were also placed on the web pages of a number of anti-stalking charities and information forums based in the UK and the USA. Respondents were assured of their anonymity and of the confidentiality of their responses prior to completing the questionnaire.

Completed surveys were submitted by victims from 24 countries. However, responses from the UK and the USA were found to not significantly differ on a range of key variables (including proportion of victim stalked by ex-intimates, frequency of experience of stalking behaviours, and sex breakdowns) and therefore only data from these two countries were included in the current analyses. The survey was lengthy and took an average of 41 minutes to complete. Very few participants (less than 50) asked for and returned a paper copy of the questionnaire, and their responses were not included as combining datasets may have increased heterogeneity. 


\section{Statistical Methods}

Relevant issues covered by the stalking questionnaire were placed into one of four categories: the nature of the stalking process, negative consequences for victims, negative consequences for third parties, and victim responses. For each of these categories, one ordinal regression was conducted using SPSS PLUM (Norušis, 2004). The predictor variable was victimperpetrator sex dyad: male-male, male-female, female-male, female-female. The outcome variables were responses to questionnaire items concerning the nature, effects of, or response to the stalking. Ordinal regression requires parallelism of the logit to be tested and this was performed in each case. All relevant variables within the categories (105 in total) were configured so that 0 represented a 'no' response or absence of a variable and 1 represented a 'yes' response or presence of a variable. As such, both closed questions with a simple 'yes/no' response and closed questions with a series of possible responses could be included in the regression analyses.

The physical violence variable was split to allow an examination of 'serious violence'. In this study serious violence equated to an injury inflicted by the stalker that required medical aid. The cell counts were very small (four cells contained less than five cases) and so the only the basic percentage values will be reported.

\section{Results}

\section{Descriptives}

Table 1 breaks down the dyads according to stalker-victim prior relationship and several sociodemographic variables.

--- Table 1 about here ---

\section{The Stalking Process}


The first ordinal regression analysed responses to questions indicating the types of stalking behaviour experienced. Goodness of fit statistics demonstrated no significant difference between the observed and expected frequencies (Pearson $\left.\chi^{2}(2540)=2615.38, p=0.15\right)$, so the overall model was a good fit to the data. There was no overall significant relationship between sex dyad and the 45 variables that covered the stalking process, as indicated by the coefficients produced by the model. Five predictors did, however, prove significant and these are shown in Table 2 below.

\section{--- Table 2 about here ---}

Male stalkers with female victims were the dyad most likely to stalk via the internet, closely followed by male stalkers with male victims. Female stalkers of both sexes were significantly less likely to harass via the web. Female stalkers of same sex victims were significantly less likely than the other three groups to take unwanted photographs of their victims. Female stalkers were more likely than male stalkers to abuse their victims' pets, particularly so when the victim was also female. Threats of sexual assault were most commonly reported by female and male victims of male stalkers. Female victims were significantly more likely to report high fear levels than were male victims. Male stalkers with female victims were most likely to inflict injuries requiring medical attention (7.8\%), followed by female stalkers with male victims $(6 \%)$, female-female stalkers (4\%) and male-male stalkers $(2.1 \%)$.

\section{Effects on Victims}

The model showed no significant difference between observed and expected values (Pearson $\left.\chi^{2}(2166)=2314.55, p=.41\right)$. As regards personal and medical sequelae, the relevant coefficients indicated that personal and medical effects on the victims significantly differed according to sex of victim and perpetrator $\left(\chi^{2}(24)=59.39 p<.001\right)$. This time, four individual predictors proved significant, and these may be seen in Table 3. 
--- Table 3 about here ---

Both male and female victims of male stalkers were more likely than victims of female stalkers to report feelings of weakness. Conversely, male and female victims of female stalkers were more likely than victims of male stalkers to report feelings of confusion. Male victims were more likely than female victims to report acting out aggressively towards their stalker, regardless of stalker sex. Male victims of female stalkers were significantly less likely than the other three dyads to report feeling a generalised distrust of others as a result of being stalked.

With regard to social and economic effects, the variables demonstrated no significant differences between observed and expected values $\left(\right.$ Pearson $\left.\chi^{2}(1682)=1702.83, p=0.36\right)$, indicating again that the model was a good fit to the data. The coefficients revealed that the model was not significant $\left(\chi^{2}(19)=18.88, p=0.46\right)$. Just one individual variable was significant, and this concerned being forced to give up social activities (Wald $(1)=5.50, p<.02$ ). Male victims of female stalkers were significantly less likely to give up social activities as a result of being targeted by a stalker.

\section{Effects on Third Parties}

No significant differences between observed and expected frequencies were revealed $\left(\right.$ Pearson $\left.\chi^{2}(1113)=1058.30 ; p=0.88\right)$. The coefficients demonstrated no overall significance of the model $\left(\chi^{2}(12)=20.30, p=0.62\right)$, and no individual predictors were significant.

\section{Victim Responses}

The model was a good fit to the data $\left(\chi^{2}(21)=20.95, p=0.46\right)$. The overall model was not significant, indicating that overall, the four dyads did not respond to their stalkers differently $\left(\right.$ Pearson $\left.\chi^{2}(443)=463.8, p=0.24\right)$. Two individual predictors were significant: responding to e- 
mails (Wald $(1)=5.31, p<.03$ ), in that victims of female stalkers were more likely to respond to emails); and the victim asking the stalker to desist (Wald (1) $=7.99, p=<.005$ ), in that male victims with a male stalker were significantly less likely to do this.

\section{Category Membership Predictions}

The PLUM ordinal regression model produced category membership predictions, allowing us to gauge which of the four dyads were most similar to one another. For the stalking process variables, the results may be seen in Table 4 .

--- Table 4 about here ---

The figures listed in Table 4 suggest that category membership can be strongly predicted by stalker sex, rather than victim sex. For instance, males who stalk males are more similar to males who stalk females than they are to females who stalk males. Category membership analyses were conducted for the other outcome variables, namely effects on victims and third parties, and victim responses. All category membership patterns were in line with those reported for the stalking process, and as such are omitted for the sake of brevity.

\section{Discussion}

The differences between the four sex dyads as revealed by the current work are few when compared with the similarities. The four dyads were compared across a range of 105 study variables, and statistically significant findings were produced for just 12 of these. As regards the stalking process, less than $9 \%$ of variables differed significantly according to stalker and victim sex. Those variables relating to the stalking process that did differ by sex dyad did so in a manner than conformed to sex role stereotypes. Male stalkers were more likely to employ technology to aid their harassment 
campaigns, threaten sexual assault, and inflict serious injuries. Socio-demographic data were also in line with sex role stereotypes, as male stalkers of female victims targeted the youngest victims, and males were most likely to stalk their female ex-partners. The female stalkers were most likely to target male singles, and females were also most likely to target professionals.

The Australian same-sex stalkers reported on by Pathé et al. (2000) were more likely to follow and approach their victims than opposite sex stalkers. Ours were not, although both the Pathé et al. work and the current findings agree that same sex and opposite sex stalkers engage in similar levels of violent and destructive behaviour. Strand and McEwan (2011) found that their same sex stalkers did not differ from their opposite sex stalkers according to age, duration of stalking, and prior relationship status. The current study supports these findings, but failed to find that same sex stalkers were more likely to threaten their victims. The most likely reason for these differences centres on the nature of the samples. Our sample comprised self-selecting victims of stalking, whilst the earlier studies focussed on stalkers referred to a forensic clinic, or cases investigated by police. It is possible, even likely, that higher severity levels are related to many other variables in same-sex cases. Furthermore, comparing data from stalkers and victims constitutes a comparison of perspectives. One consequence of this is that victims may not be aware of some of the behaviours that their stalker engaged in. Because of these sampling differences, comparisons must only be made very cautiously. Perhaps the most important point to take away from what is so far known about the process of same-sex stalking is that it is more similar to than it is different from oppositesex stalking.

In terms of the negative consequences for victims, the statistical model did show an overall significant influence of sex. This was true for physical and psychological sequelae only, not economic and social consequences. Male victims of both stalker sexes were more likely than females to adopt an aggressive coping style, and this would fit well with the lower fear levels reported by male victims and Western expectations concerning gendered behaviour. Also in line with sex stereotypes, both sexes reported significantly more confusion when targeted by a female 
stalker. Again, this reaction fits with stereotypes concerning male perpetration and female victimisation. In keeping with a scene from a well known Hollywood stalker film, we found that female stalkers were more likely to abuse their victim's pet animals than were male stalkers. Within each dyad, the family, friends, and neighbours of the victim and other persons connected with the victim were equally likely to suffer the adverse consequences of stalking. Perhaps it is the case that factors other than sex (for instance, duration of stalking or level of threat) are good predictors of the effects on third parties. Given high base rates of stalking, its impact on third parties is a worthy avenue of future research.

As mentioned above, female victims reported higher levels of fear than did male victims. It is worth noting here a study of 1,214 stalking victims based in the USA and the UK that assessed the predictors of a range of social, economic, psychological and physical consequences (Sheridan \& Lyndon, 2010). The most important predictor of negative consequences was fear, with women being more fearful than men. Our females also reported higher levels of long term fear, in that male victims of female stalkers reported significantly less generalised distrust than did the other dyads. Female victims of males felt most weakened by the stalking, which would also fit with being fearful, as does the finding that male victims of female stalkers were significantly less likely to give up social activities after being targeted by a stalker. Female stalkers may make their victims less fearful and/or female victims may feel more fear, and future work should seek to examine how far gendered perceptions of fear in stalking cases differ from the realties. Although male victims reported less fear, they were equally as likely as females to make a report to police. In fact, all four sex dyads were taken equally seriously by a range of professional and non professional groups. It is worth noting here that if one or more dyads are far less likely to self-identify as a stalking vicim, then they wouldn't have completed the study questionnaire (although McNamara and Marsil's 2012 findings would argue against this notion).

Despite marked differences in fear levels, only two of a range of victim responses to being stalked proved significant. That is, female victims were more likely to reply to e-mails than male 
victims, and male victims of male stalkers were least likely to ask stalkers to desist. All four dyads were found to be equally violent. Because earlier studies (e.g. James \& Farnham, 2003) have found that sex differences are more marked in cases of serious violence, we sought to examine this. Only basic percentages could be produced as some of the numbers were too low to allow robust analysis. Male stalkers of females were most likely to commit serious violence, but male-male stalkers were the least seriously violent dyad. Our very small numbers support the prior research on sex and serious violence (but see Thompson et al., 2012). This goes some was to explaining the apparent paradox in that despite similar base rates for male and female stalker violence violence, women victims report more fear. If female stalkers are less likely to engage in serious violence, this would also explain why male victims were more likely to respond to their stalkers in an aggressive manner. Future work should examine whether acting out aggressively curtails or encourages further violence within a case of stalking.

None of our sex dyads differed significantly in terms of prior victim-stalker relationship, perceived motivations and triggers, whether the stalker was aided by third parties, whether the victim was physically assaulted, received threats, had property destroyed, was forced to change identify or relocate, had to pay various stalking related expenses (therapeutic, legal, security), had stalking-related problems at work, and whether the victim suffered a range of physical and psychological sequelae such as suicide attempts, depression, sleep disturbances, self-harm, physical injuries and panic attacks. Strand and McEwan (2012) concluded that prior relationship and motivation were more important than sex in terms of contribution to the course and nature of a stalking episode. Of course, the importance of sex, prior relationship, and motivation were not directly compared here. It is suggested that future work add another level of comparison, namely the stalker-victim prior relationship, as interactions between core variables may increase not complexity but our understanding of the dynamics of stalking victimisation.

When attempting to evaluate and generalise from the present findings, some issues need to be highlighted. Suspicious cases were deleted following strict criteria, but the problems associated 
with a self defining sample remain. We were not able to corroborate responses, the sample may be biased in favour of the more severely stalked, and those unwilling to complete a lengthy questionnaire self excluded. The positive aspects of large scale surveys of stalking victims include access to a large variety of respondents, inclusion of those unwilling to have physical meetings or speak with researchers, extending studies in the field from research based on clinical and forensic data, recording information on both prosecuted and non-prosecuted cases, reduction of demand characteristics and an increase in disclosure. Support for on-line research has been provided by, for instance, Gosling, Vazire, Srivastava and John (2004). After noting scepticism concerning internet data collection methods, these authors compared a web sample of 361,703 respondents with data collected via 510 studies employing more traditional methodologies. It was concluded that the internet data are "at least as diverse as many of the samples already used in psychological research and are not unusually maladjusted" (p. 102). It was further argued that internet samples were no less representative than traditional samples, nor tainted by false responders. One more issue that may affect generalisability concerns group proportions. The proportion of females targeted by females was roughly commensurate with the proportion identified by both smaller previous studies and large scale epidemiological surveys. Our number of men stalked by men was far lower, however, and our number of males stalked by females was much higher. There was also an unbalanced distribution between groups, and specifically male stalkers and female victims were overrepresented.

In conclusion, the current work compared four sex dyads across a range of stalking related variables. Far more similarities than differences were seen, and those differences that did exist tended to conform to sex stereotypes. Both Strand and McEwan (2011) and Pathé et al. (2000) concluded that prior stalker-victim relationship and motivation for stalking were more important factors than sex when assessing the process of stalking. Sheridan and Lyndon (2012) found victim fear to be a greater predictor of negative consequences for stalking victims that sex and prior relationship. Combined with the current findings, it may be that more traditional risk factors such as 
sex and relationship status may be less important than the experiences and feelings of victims. Victims are a valuable resource who can often be sidelined in the collection of evidence, risk assessment, and management of stalking cases. Future work should focus on the ability of victims to assess their own risk. Those who investigate stalking cases should focus on actual stalking behaviour and its impact rather than on sex, and acknowledge that sex role conformity may influence reactions to being the victim of a stalker. 


\section{References}

Australian Bureau of Statistics. (2010). Customised report. Based on data from the 2005 Personal Safety Survey. Australian Bureau of Statistics.

Baum, K., Catalano, S., Rand, M., \& Rose, K. (2009). Stalking victimization in the United States. Washington DC: US Department of Justice, Office of Justice Programs.

Bjerregaard, B. (2002). An empirical study of stalking victimization. In K. E. Davis, I. Frieze, R. D. Maiuro (Eds.), Stalking: Perspectives on victims and perpetrators (pp. 112-137). New York: Springer.

Budd, T., \& Mattinson, J. (2000). Stalking: Findings from the 1998 British Crime Survey. London: Home Office Research, Development and Statistics Directorate.

Davis, K. E., Frieze, I. H., \& Maiuro, R.D. (2002). Stalking: Perspectives on victims and perpetrators. New York: Springer.

Derlega, V.J., Winstead, B.A., Pearson, M.R., Janda, L.J., Lewis, R.J., Dutton, L.B., Ferrer, R., \& Greene, K. (2011). Unwanted pursuit in same-sex relationships: Effects of attachment styles, investment model variables, and sexual minority stressors. Partner Abuse, 2, 300322. doi: $10.1891 / 1946-6560.2 .3 .300$.

Dutton, L. B., \& Winstead, B. A. (2006). Predicting unwanted pursuit: Attachment, relationship satisfaction, relationship alternatives, and break-up distress. Journal of Social and Personal Relationships, 23, 565-586. doi: 10.1177/0265407506065984.

Englebrecht, C.M., \& Reyns, B.W. (2011). Gender differences in acknowledgment of stalking victimization: Results from the NCVS Stalking Supplement. Violence and Victims, 26, 560579. doi: 10.1177/0011128712461123.

Gosling, S.D., Vazire, S., Srivastava, S., \& John, O.P. (2004). Should we trust web-based studies? A comparative analysis of six preconceptions about internet questionnaires. American Psychologist, 59, 93-104. doi: 10.1037/0003-066X.58.8.663. 
Harmon, R. B., Rosner, R., \& Owens, H. (1998). Sex and violence in a forensic population of obsessional harassers. Psychology, Public Policy and Law, 4, 236-249. DOI:10.1037/10768971.4.1-2.236.

Hoffmann, J., \& Sheridan, L. (2008). Celebrities as victims of stalking. In Meloy, J. R., Sheridan, L., \& Hoffmann, J. (Eds.). (2008). Stalking, threatening and attacking public figures. New York: Oxford University Press.

James, D.V., \& Farnham, F.R. (2003). Stalking and serious violence. Journal of the American Academy of Psychiatry and the Law, 31, 432-439. doi: 10.1002/bsl.922.

McNamara, C.L., \& Marsil, D. (2012). The prevalence of stalking among college students: The disparity between researcher- and self-identified victimization. Journal of American College Health, 60, 168-174. doi: 10.1080/07448481.2011.584335.

Meloy, J.R. (1999). Stalking: An old behavior, a new crime. Psychiatric Clinics of North America, 22, 85-99.

Meloy, J. R., \& Boyd, C. (2003). Female stalkers and their victims. Journal of the American Academy of Psychiatry and the Law, 31, 211-219.

Meloy, J.R., Mohandie, K., \& Green, M. (2011). The female stalker. Behavioral Sciences and the Law, 29, 240-254. doi: 10.1002/bs1.976.

Mullen, P. E., Pathé, M., \& Purcell, R. (2009). Stalkers and their victims (2nd ed.). New York, NY: Cambridge University Press; US.

Nicastro, A.M., Cousins, A.V., \& Spitzberg, B.H. (2000). The tactical face of stalking. Journal of Criminal Justice, 28, 69-82.

Norušis, M.J. (2004). SPSS 13.0: Advanced statistical procedures companion. New Jersey: Prentice Hall.

Pathé, M., Mullen, P. E., \& Purcell, R. (2000). Same-gender stalking. Journal of the American Academy of Psychiatry and the Law, 28, 191-197. 
Purcell, R., Pathé, M., \& Mullen, P. E. (2001). A study of women who stalk. The American Journal of Psychiatry, 158, 2056-2060.

Purcell, R., Pathé, M., \& Mullen, P.E. (2002). The incidence and nature of stalking in the Australian community. Australian and New Zealand Journal of Psychiatry, 36, 114-120.

Reavis, J., Allen, E., \& Meloy, J. R. (2008). Psychopathy in a mixed gender sample of adult stalkers. Journal of Forensic Sciences, 53, 1214-1217. doi: 10.1111/j.15564029.2008.00839.x.

Rosenfeld, B. (2004). Violence risk factors in stalking and obsessional harassment: A review and preliminary meta-analysis. Criminal Justice and Behavior, 31, 9-36. doi: $10.1177 / 0093854803259241$.

Rosenfeld, B., \& Lewis, C. (2005). Assessing violence risk in stalking cases: A regression tree approach. Law and Human Behavior, 29, 343-357. doi: 10.1007/s10979-005-3318-6.

Rusbult, C. E., Martz, J. M., \& Agnew, C. R. (1998). The Investment Model Scale: Measuring commitment level, satisfaction level, quality of alternatives, and investment size. Personal Relationships, 5, 357-391. doi: 10.1111/j.1475-6811.1998.tb00177.x.

Sheridan, L. and Grant, T. (2007). Is cyberstalking different? Psychology, Crime and Law, 13, 627640. doi:10.1080/10683160701340528.

Sheridan, L., \& Lyndon, A. E. (2012). The influence of prior relationship, gender, and fear on the consequences of stalking victimization. Sex Roles, 66, 340-350. doi:10.1007/s11199-0109889-9.

Sinclair, H. C., \& Frieze, I. H. (2002). Initial courtship behaviour and stalking: How should we draw the line? In J. A. Davis, I. H. Frieze, \& R. D. Maiuro (Eds.), Stalking: Perspectives on victims and perpetrators (pp. 186-211). New York: Springer Publishing Company.

Spitzberg, B.H., \& Cupach, W.R. (2007). The state of the art of stalking: Taking stock of the emerging literature. Aggression and Violent Behavior, 12, 64-86. doi: $10.1080 / 08934215.2011 .61373$ 
Strand, S., \& McEwan, T.E. (2011). Same-gender stalking in Sweden and Australia. Behavioral Sciences and the Law, 29, 202-219. doi: 10.1002/bsl.981.

Strand, S., \& McEwan, T.E. (2012). Violence among female stalkers. Psychological Medicine, 42, 545-555. doi: 10.1017/S0033291711001498.

Thomas, S. D. M., Purcell, R., Pathé, M., \& Mullen, P. E. (2008). Harm associated with stalking victimization. Australian and New Zealand Journal of Psychiatry, 42, 800-806. doi: 10.1080/ 00048670802277230.

Thompson, C.M., Dennison, S.M., \& Stewart, A. (2012). Are female stalkers more violent than male stalkers? Understanding gender differences in stalking violence using contemporary sociocultural beliefs. Sex Roles, 66, 351-365. doi:10.1007/s11199-010-9911-2.

Tjaden, P., \& Thoennes, N. (1998). Stalking in America: Findings from the National Violence Against Women Survey. Washington, DC: National Institute of Justice. 
Table 1. Prior Relationship and Socio-demographic Details by Dyad

\begin{tabular}{|c|c|c|}
\hline & Sex of stalker: Male & Sex of stalker: Female \\
\hline Sex of victim: Male & $\begin{array}{l}21.4 \% \text { ex partners } \\
59.5 \% \text { acquaintances } \\
19 \% \text { strangers } \\
\text { Victim age } 33.43 \text { (SD 13.08) } \\
56.6 \% \text { of victims single } \\
80 \% \text { of victims white } \\
22.9 \% \text { of victims professionals } \\
8.6 \% \text { of victims unemployed } \\
14.3 \% \text { of victims students }\end{array}$ & $\begin{array}{l}43.1 \% \text { ex partners } \\
44.4 \% \text { acquaintances } \\
12.5 \% \text { strangers } \\
\text { Victim age } 34.52 \text { (SD 10.76) } \\
65.7 \% \text { of victims single } \\
91.9 \% \text { of victims white } 22.9 \% \\
44.4 \% \text { of victims professionals } \\
7.9 \% \text { of victims unemployed } \\
7.9 \% \text { of victims students }\end{array}$ \\
\hline Sex of victim: Female & $\begin{array}{l}52.7 \% \text { ex partners } \\
34.7 \% \text { acquaintances } \\
12.5 \% \text { strangers } \\
\text { Victim age } 30.89 \text { (SD 10.20) } \\
60.2 \% \text { of victims single } \\
93.1 \% \text { of victims white } \\
28.5 \% \text { of victims professionals } \\
4.6 \% \text { of victims unemployed } \\
16.6 \% \text { of victims students }\end{array}$ & $\begin{array}{l}17.7 \% \text { ex partners } \\
67.7 \% \text { acquaintances } \\
14.6 \% \text { strangers } \\
\text { Victim age } 34.97 \text { (SD 13.10) } \\
46 \% \text { of victims single } \\
94.9 \% \text { of victims white } \\
26 \% \text { of victims professionals } \\
5.2 \% \text { of victims unemployed } \\
16.9 \% \text { of victims students }\end{array}$ \\
\hline
\end{tabular}


Table 2. Parameter Estimates for Stalking Process

Stalked via the internet

Took photographs of the victim

Abused the victim's pets

Threatened to sexually assault victim

How frightened the victim was
Estimate Wald df Sig.

\begin{tabular}{|c|c|c|}
\hline-20.63 & 218.47 & $1<.001$ \\
\hline 1.33 & 12.67 & $1<.001$ \\
\hline-1.37 & 7.62 & $1<.006$ \\
\hline 0.99 & 4.01 & $1<.05$ \\
\hline-0.95 & 4.13 & $1<.04$ \\
\hline
\end{tabular}


Table 3. Parameter Estimates for Personal Effects on Victims

Estimate Wald df Sig.

Victim acted out aggressively

$0.75 \quad 4.92 \quad 1<.003$

Victim suffered feelings of weakness

$1.07 \quad 7.58 \quad 1<.006$

Victim suffered feelings of confusion

$\begin{array}{lll}-0.82 & 7.17 \quad 1<.007\end{array}$

Victim became distrustful of others

$\begin{array}{llll}0.82 & 5.14 & 1 & <.04\end{array}$ 
Table 4. Category Membership Predictions

\begin{tabular}{|l|l|l|l|l|}
\hline \multirow{2}{*}{} & \multicolumn{3}{|c|}{$\begin{array}{l}\text { Male stalker/male } \\
\text { Female } \\
\text { stalker/female } \\
\text { victim }\end{array}$} & $\begin{array}{l}\text { Female } \\
\text { stalker/male victim } \\
\text { victim } \\
\text { stalker/female } \\
\text { victim }\end{array}$ \\
\hline $\begin{array}{l}\text { Actual category } \\
\text { membership }\end{array}$ & & & & \\
\hline $\begin{array}{l}\text { Female } \\
\text { stalker/female } \\
\text { victim }\end{array}$ & $\mathbf{5 8 . 3 \%}$ & $22.9 \%$ & $6.2 \%$ & $12.5 \%$ \\
\hline $\begin{array}{l}\text { Female } \\
\text { stalker/male victim }\end{array}$ & $27.8 \%$ & $\mathbf{3 3 . 3 \%}$ & $13 \%$ & $25.9 \%$ \\
\hline $\begin{array}{l}\text { Male stalker/male } \\
\text { victim }\end{array}$ & $2.1 \%$ & $19.1 \%$ & $\mathbf{5 1 . 1 \%}$ & $\mathbf{2 7 . 7 \%}$ \\
\hline $\begin{array}{l}\text { Male } \\
\text { stalker/female } \\
\text { victim }\end{array}$ & $9.8 \%$ & $29.3 \%$ & $25.9 \%$ & $\mathbf{3 6 . 6 \%}$ \\
\hline
\end{tabular}

